\title{
COX-2 Specific Inhibitor, NS-398, Increases Macrophage Migration Inhibitory Factor Expression and Induces Neuroendocrine Differentiation in C4-2b Prostate Cancer Cells
}

\author{
Katherine Meyer-Siegler \\ Department of Research and Development, Bay Pines Veteran's Administration Medical Center, Bay Pines, FL \\ University of South Florida College of Medicine, Department of Surgery, Tampa, FL \\ Accepted November 19, 2001
}

\begin{abstract}
Background: Cyclooxygenase-2 (COX-2) is an inducible enzyme involved in the conversion of arachadonic acid to prostaglandins and other eicosaniods. Persistent COX-2 expression is associated with multiple forms of cancer. Therefore, there is much interest in COX-2 specific, non-steroidal anti-inflammatory drug use for cancer chemotherapy. The mechanism by which these drugs inhibit tumor growth and progression is unclear, and our knowledge about their potential to prevent or treat prostate cancer is inadequate.

Materials and Methods: The effects of NS-398, a selective COX-2 inhibitor, on human prostate carcinoma cell line LNCaP and the LNCaP subline C4-2b were investigated in this study. NS-398 effects on apoptosis were examined by caspase- 3 activity increase, as well as internucleosomal cleavage. ELISA and PCR were used to determine inhibitor effects on macrophage migration inhibitory factor (MIF) and COX-2 production.

Results: At $10 \mu \mathrm{M}$, NS-398 treatment resulted in increased production of COX-2 and the pro-inflammatory
\end{abstract}

cytokine, MIF by the C4-2b LNCaP subline. NS-398 $(10 \mu \mathrm{M})$ induces apoptosis in LNCaP cells, but not in the more aggressive, androgen-unresponsive $C 4-2 b$ cells. The C4-2b cells were observed to continue to proliferate when treated with NS-398 and continued to retain malignant phenotype characteristics. NS-398 treatment resulted in $\mathrm{C} 4-2 \mathrm{~b}$ cell differentiation into an unusual neuroendocrinelike cell. These neuroendocrine-like cells produced both epithelial (cytokeratin 18 and prostate specific antigen) and neuronal (neuron-specific enolase and chromogranin A) proteins. Furthermore, this $C 4-2 b$ cellular response to NS-398 was mediated by $N F-\kappa \beta$ transcription factor activation.

Conclusions: These data suggest that COX-2 inhibition induces NF- $\kappa \beta$ transcription factor activation, which subsequently induces pro-inflammatory protein expression (COX-2 and MIF) and neuroendocrine differentiation in the LNCaP C4-2b subline. These data provide further evidence that pro-inflammatory protein expression may play an important role in prostate cancer progression.

\section{Introduction}

In the United States, prostate cancer is the most common malignancy and second leading cancer-related death cause in males. Current metastatic prostate cancer treatment is based on androgen ablation, which initially results in reduced tumor cell growth, apoptosis and temporary symptom regression. This treatment modality usually results in aggressive androgen-unresponsive relapse that is resistant to further hormonal manipulation or conventional chemotherapy. Androgen non-responsive prostate cancer is heterogeneous, resists apoptosis, proliferates and metastasizes despite hormone depletion. Recent efforts to develop new therapeutic strategies for prostate cancer treatment have involved the utility of non-steroidal anti-inflammatory drugs (NSAIDs). NSAIDs are commonly prescribed drugs for inflammation control. However, these drugs have demonstrated

Address correspondence and reprint requests to: Katherine Meyer-Siegler, Bay Pines VAMC, P.O. Box 5005, Bay Pines, FL, 33744. Phone: (727) 398-6661, ext. 5236; fax: (727) 398-9467; e-mail: ksiegler@hsc.usf.edu. anticancer activity. Recent studies indicated that men who regularly took NSAIDs exhibited a reduced risk of prostate cancer development (1). The mechanism by which these drugs inhibit tumor growth and progression is unclear, and our knowledge about their potential to treat prostate cancer is inadequate.

It has been suggested for decades that chronic inflammatory reactions in tissue result in increased carcinoma development risk. Excessive cell death is often associated with inflammation, whereas increased cell survival under these conditions contributes to cancer outgrowth (2). Studies have associated increased inflammatory protein expression with cancer development (3-5) and inflammatory gene inhibition is associated with cancer prevention (6-8). In particular, studies from this laboratory have identified increased macrophage migration inhibitory factor (MIF) expression, a pro-inflammatory cytokine, with metastatic prostate cancer $(5,9)$. Recent studies have associated increased COX-2 expression, a proinflammatory enzyme, with prostate, as well as other cancers $(3,4,8,10-12)$. The COX enzyme exists in two 
isoforms, COX-1, which is constitutively produced and COX-2, the inducible form. COX-2 is induced by a variety of factors including various cytokines, growth factors and tumor promoters (13). A recent study has determined that MIF up-regulates COX activity and specifically induces COX-2 gene expression in synoviocytes (14). COX-2 can be induced under normal conditions in the prostate (13). However, COX-2 overexpression in prostate epithelial cells was reported to inhibit apoptosis and increases malignant cell invasiveness (15). Attempts to identify specific COX-2 transcriptional mediators that regulate gene expression and the mechanism(s) by which NSAIDs modulate tumorigenesis are the current investigational focus of many laboratories.

Until recently very little attention has been given to COX-2 and MIF function in the prostate and its relationship to prostate cancer. In this study the LNCaP metastatic prostate cancer cell model is used to elucidate NS-398 effects on cells that span human prostate cancer stage extremes in genetically related cells (LNCaP parental and LNCaP C4-2b subline) (16). This study's aim is to determine if NS-398, a COX-2 specific inhibitor, induces prostate cancer cell apoptosis in the androgen-unresponsive, highly aggressive C4-2b LNCaP subline; a second aim is to investigate NS-398's effect on MIF and COX-2 expression in these prostate cancer cells.

\section{Materials and Methods} Cell Culture

LNCaP cell line was obtained from the American Type Culture Collection (Manassas, VA). LNCaP C4$2 \mathrm{~b}$ cell line was obtained from UroCore (Oklahoma City, OK). Cells were routinely cultured in growth medium, which consisted of Prostate Epithelial Basal Medium (PrEBM, Clonetics, San Diego, CA) with $5 \%$ heat inactivated charcoal-stripped fetal bovine serum (FBS, GIBCO-BRL, Grand Island, NY) supplemented with $5 \mu \mathrm{g} / \mathrm{ml}$ insulin, $13.7 \mathrm{pg} / \mathrm{ml}$ triiodothyronine, $5 \mu \mathrm{g} / \mathrm{ml}$ apo-transferrin, $0.24 \mu \mathrm{g} / \mathrm{ml}$ biotin, $25 \mu \mathrm{g} / \mathrm{ml}$ adenine, 100 units penicillin and $100 \mu \mathrm{g} / \mathrm{ml}$ streptomycin. All supplements were filter sterilized and purchased from Sigma (St. Louis, MO). Cells were routinely cultured at $37^{\circ} \mathrm{C}$ in an incubator equilibrated with $5 \% \mathrm{CO}_{2}$.

\section{Chemicals}

Cytokeratin 18 specific antibody (A-3563) and DMSO were obtained from Sigma. NS-398, isotype specific goat IgGl control antibody and COX-2 specific antibodies (160107) were obtained from Cayman Chemicals (Ann Arbor, MI). Anti-human MIF antibodies and recombinant protein were obtained from R\&D Systems (Minneapolis, MN). NF- $\kappa \beta$ specific inhibitor SN-50 and SN-50M inactive control peptide were obtained from Calbiochem (San Diego, CA). I $\kappa \beta-\alpha$ antibody, NF- $\kappa \beta$ p65 antibodies were from Santa Cruz Biotechnology (Santa Cruz, CA).
PSA antibody (AB568), and chromogranin A antibody (MAB3 19) were from Chemicon International (Temecula, CA).

\section{Cell Viability Assay}

$1 \times 10^{6}$ cells were plated in six well cluster plates with $2 \mathrm{ml}$ of medium for $24 \mathrm{~h}$. At time point 0 , medium was removed, cells were carefully washed with phosphate buffered saline (PBS) and serum free (SF), phenol-red free medium containing $0.5 \mu \mathrm{g} / \mathrm{ml}$ BSA was added. Incubations were continued for an additional $72 \mathrm{~h}$ with or without increasing NS-398 concentrations (17). NS-398 stocks ( $5 \mathrm{mM}$ ) were dissolved in $0.1 \%$ dimethylsulfoxide (DMSO). Cells and culture medium were harvested at $24 \mathrm{~h}$ time intervals. Dead cells were removed by gentle washing with PBS and cell number determined by direct counting using trypan blue dye exclusion to identify viable cells. DMSO $(0.1 \%)$ was added to control cultures.

\section{Clonogenicity}

NS-398 effects on cell division were assessed by NS-398 inclusion in SF PrEBM containing $0.5 \mu \mathrm{g} / \mathrm{ml}$ BSA. Cells at $80 \%$ confluence were treated for $48 \mathrm{~h}$ with NS-398 $(10 \mu \mathrm{M})$. Cells were then trypsinized at $24 \mathrm{~h}$ intervals and seeded $\left(20\right.$ cells $\left./ \mathrm{cm}^{2}\right)$ in 96 well plates in growth medium. Two plates per treatment and vehicle control (DMSO) were analyzed. Fresh medium was added 5 days after seeding and cell number assessed following 10 days growth by MTS assay (Promega, Madison, WI). Relative cell number per well in the 96 well plate was determined as described previously (18).

\section{Morphological Assessment}

$1 \times 10^{3}$ cells were plated in 8 -well chamber slides (Nunc, Inc, Naperville, IL) with $0.5 \mathrm{ml}$ cell growth medium with or without $10 \mu \mathrm{M}$ NS-398. Control cultures contained $0.1 \%$ DMSO. Cells were observed microscopically at $24 \mathrm{~h}$ intervals. Changes in morphology were documented using a microscope mounted digital cameral (Cool Snap, RS Photometrics, San Diego, CA) and the AlphaInnotech 2200 Imaging System (AlphaInnotech, San Leandro, CA). Morphological changes were quantified by using the manual counting feature to count cells with characteristic neuron-like morphologies. At least 200 cells were examined in each of the eight chambers for each time point. Morphological changes specific to increasing MIF concentrations were determined by MIF polyclonal neutralizing antibody (R\&D systems, goat-polyclonal) inclusion at a 1:200 dilution. Controls for these experiments included the addition of isotype specific goat IgGl control antibody at a 1:200 dilution. These experiments were performed in triplicate.

\section{Qualitative DNA Fragmentation}

Subconfluent cells were treated with NS-398 (10 $\mu \mathrm{M})$ for $72 \mathrm{~h}$. Adherent cells were harvested by trypsin and 
pooled with detached cells in the culture medium. Following centrifugation $\left(2,000 \mathrm{~g}\right.$ for $5 \mathrm{~min}$ at $\left.4^{\circ} \mathrm{C}\right)$ cells were washed with cold PBS, lysed in lysis buffer (100 mM NaCl, $100 \mathrm{mM}$ Tris (pH 8.0), 25 mM EDTA, $0.5 \%$ SDS and $100 \mu \mathrm{g} / \mathrm{ml}$ proteinase $\mathrm{K}$ ), and $20 \mu \mathrm{g}$ purified DNA separated on $1.5 \%$ agarose gels using TAE buffer and analyzed as described (17).

\section{ELISA and Western Blotting}

MIF was quantified using a sandwich ELISA previously described (18). Prostate specific antigen (PSA) in culture medium was assayed by indirect ELISA by diluting conditioned medium 1:1 with $50 \mathrm{mM}$ carbonate buffer $\mathrm{pH} 9.0$ followed by distribution of $50 \mu \mathrm{l}$ aliquots into triplicate wells in 96 well plates followed by incubation overnight at $4^{\circ} \mathrm{C}$. Antigen solution was then removed, non-specific protein binding blocked by $\mathrm{l} \mathrm{h}$ incubation with milk diluent buffer (1:20 dilution) (Kirkegaard \& Perry Laboratories, Gaithersburg, MD) and PSA detected using rabbit anti-human PSA polyclonal antibody (1:1000). Alkaline phosphatase conjugated anti-rabbit IgG (1:10000, Sigma A2306) and BluePhos substrate (Kirkegaard \& Perry Laboratories) was used to quantify antigen in samples. PSA (purified human protein, AG650, Chemicon International) standard curve was generated using serially diluted PSA at concentrations starting from $125 \mathrm{ng} / \mathrm{ml}$. ELISA for COX-2, chromogranin A and neuron specific enolase (NSE) were developed as per PSA ELISA using antigen specific antibodies (1:1000 dilutions) and appropriate secondary antibody conjugates. Western blots were performed using the general protocols as outlined previously (19). SDS-polyacrylamide gel samples were prepared so that the final total protein concentration equaled $30 \mu \mathrm{g} / \mathrm{ml}$.

\section{Relative Quantitative RT-PCR}

cDNA was reverse transcribed from $1 \mu \mathrm{g}$ total cellular RNA using random decamers and Moloney-Murine Leukemia Virus reverse Transcriptase (Ambion, Austin, TX) as described (19). Gene specific primer (50 pmole $3^{\prime}$ and $5^{\prime}$ ) was mixed with 3:7 18S primer/Competimer mix (Ambion). The generated 488 bp 18 S rRNA PCR fragment was used as an internal standard to quantify gene specific PCR products. COX-2 specific PCR primers were forward: 5' CCAGTATAAGTGCGATTGTACC 3' and reverse: 5' CCGTAGATGCTCAGGGACTTGA 3', while the MIF PCR primers were as described previously (19). MIF amplification reactions resulted in the amplification of a $254 \mathrm{bp}$ fragment and were carried out in 25 sequential cycles of $94^{\circ} \mathrm{C}$ for $60 \mathrm{sec}, 55^{\circ} \mathrm{C}$ for $60 \mathrm{sec}$, and $72^{\circ} \mathrm{C}$ for $60 \mathrm{sec}$, followed by $72^{\circ} \mathrm{C}$ for $10 \mathrm{~min}$. COX-2 amplifications resulted in a $696 \mathrm{bp}$ fragment. COX-2 reactions were carried out in 30 sequential cycles of $94^{\circ} \mathrm{C} 30 \mathrm{sec}, 53^{\circ} \mathrm{C} 30 \mathrm{sec}, 72^{\circ} \mathrm{C}$ $60 \mathrm{sec}$, followed by $72^{\circ} \mathrm{C}$ for $10 \mathrm{~min}$. DNA bands were resolved on $2 \%$ agarose TAE gels and quantified using the AlphaInnotech 2200 imaging system.
Data are expressed as the mean gene expression ratio defined as gene-specific (MIF or COX-2) band area-intensity divided by $18 \mathrm{~S}$ rRNA band areaintensity \pm standard error of three separate PCR assays from three separate experiments. RT reaction was controlled by absence of mRNA from RT reaction tube, while the PCR reaction was controlled by absence of gene-specific (MIF or COX-2) primer.

\section{DEVDase Activity}

Caspase-3 activity was measured using a colorimetric protease assay in which the chromophore p-nitroanilide (pNA) is conjugated to the synthetic peptide Asp-Glu-Val-Asp (DEVD, BioSource International, Camarillo, CA). DEVD is the upstream caspase- 3 amino acid sequence cleaved in poly-ADP ribose polymerase (PARP). Cells were lysed in buffer [10 mM Tris-HCl (pH 8), 1\% Triton X-100, $0.32 \mathrm{M}$ sucrose, $5 \mathrm{mM}$ EDTA, plus protease inhibitors (Gibco/BRL)] for $1 \mathrm{~h}$ at $4^{\circ} \mathrm{C} .3 \mu \mathrm{g}$ total cell lysate was used to determine caspase-3 activity. Free pNA was quantified by absorbance at $405 \mathrm{~nm}$ using an ELISA plate reader. Data are expressed as pNA optical density units per $\mathrm{mg}$ total protein in NS-398 treated cultures compared with vehicle (DMSO) treated control. Total protein in cell lysates was determined by the Bradford method (20).

\section{Inhibition of NF- $\kappa \beta$ Nuclear Translocation}

$1 \times 10^{6}$ cells were plated in six well cluster plates with $2 \mathrm{ml}$ of medium for $24 \mathrm{~h}$. At time point 0 , medium was removed, cells were carefully washed with phosphate buffered saline (PBS) and serum free (SF), phenol-red free medium containing $0.5 \mu \mathrm{g} / \mathrm{ml}$ BSA was added. Incubations were continued for an additional 3 days with or without $10 \mu \mathrm{M}$ NS-398. NF- $\kappa \beta$ nuclear translocation inhibitor peptide $\mathrm{SN}-50(25 \mu \mathrm{g} / \mathrm{ml})$ or the control peptide SN-50M $(25 \mu \mathrm{g} / \mathrm{ml})$ was added in addition to NS398. Incubations were continued for an additional 3 days. Cells were harvested at $24 \mathrm{~h}$ time intervals and analyzed for MIF and cox-2 mRNA amounts. Two plates per treatment and vehicle control were analyzed and the experiment performed in duplicate.

\section{Electrophoretic Mobility Assay (EMSA)}

The presence of a NF- $\kappa \beta$ binding site within the human MIF gene promoter was established by a database search. MatInspector software (available online at http://www.molbiol.ox.ac.uk/documentation/MatInspector.html) was used to search the known human MIF promoter region for NF- $\kappa \beta$ binding sites. A putative site was found at $-485 \mathrm{bp}$ based upon the published genomic sequence (GenBank L19686, chromosome 22:20881614-20882613). Treated C4-2b cells (10 $\mu$ M NS-398 and DMSO control, $72 \mathrm{~h}$ ) were washed with ice cold PBS, harvested by scraping and centrifugation (2,000 $\mathrm{g}$ for $15 \mathrm{~min})$. Cells were lysed in buffer (10 mM HEPES pH 7.6, 
$10 \mathrm{mM} \mathrm{KCl}, 0.1 \mathrm{mM}$ EDTA, $1.5 \mathrm{mM} \mathrm{MgCl}_{2}, 0.2 \%$ NP-40, $1 \mathrm{mM}$ dithiolthreitol (DTT) and $0.5 \mathrm{mM}$ phenylmethylsufonylfluoride (PMSF). The nuclear pellet was resuspended in buffer $(20 \mathrm{mM}$ HEPES $\mathrm{pH}$ $7.9,20 \%(\mathrm{v} / \mathrm{v})$ glycerol, $100 \mathrm{mM} \mathrm{KCl}, 0.2 \mathrm{mM}$ EDTA, $0.2 \mathrm{mM}$ PMSF and $0.2 \mathrm{mM}$ DTT). NF- $\kappa \beta$ binding activity was determined an assay that detects protein binding to a double stranded oligonucleotide that contains tandem repeats of the NF- $\kappa \beta$ consensus sequence: GGGGACTTTCC (Life Technologies, Rockville, MD). Controls included addition of a specific competitor oligonucleotide for the NF- $\kappa \beta$ binding site, addition of MIF neutralizing antibody (1:200 dilution) and isotype specific goat IgGl control antibody (1:200 dilution). Samples were subjected to electrophoresis on a non-denaturing $6 \%$ polyacrylamide gel at $150 \mathrm{~V}$ at room temperature for $1.5 \mathrm{~h}$. Gels were dried under vacuum at $80^{\circ} \mathrm{C}$ for $\mathrm{l} \mathrm{h}$ then exposed to X-OMAT film overnight at $-80^{\circ} \mathrm{C}$ with intensifying screens.

\section{Data Analysis}

Raw data were compiled and used to determine means, standard deviations (SD), standard error of the means (SEM) and ranges. Analysis of variance (ANOVA) was used for grouped variables, while Student's t-test was used for paired variables. Regressions, ANOVA and Student's t-tests were calculated using SigmaStat (SPSS, Chicago, IL). Gel band intensities were quantified by direct areaintensity measurements using a digital imaging system (AlphaImager 2200 AlphaInnotech, San Leandro, CA) and SigmaScan Pro image analysis software (SPSS). In all instances significance is determined at an $\alpha=0.05$ and all data is reported as the mean \pm SEM.

\section{Results}

\section{Effects of NS398 on LNCaP and C4-2b}

Viability and Growth

Initial experiments compared NS-398 effects on LNCaP and C4-2b viability. As shown in Fig. 1 LNCaP cell treatment with $10 \mu \mathrm{M}$ NS-398 results in a significant decrease ( $85 \%$ compared with control; Student's t-test, $P=0.008$ ) in total viable cells within $48 \mathrm{~h}$, as measured by trypan blue dye exclusion direct cell counting. In contrast, $10 \mu \mathrm{M}$ NS-398 treatment of C4-2b cells resulted in no significant change in total cell numbers when compared to vehicle control cultures following 72 h NS-398 treatment $(\mathrm{P}=0.064$, power $=0.499)$.

Cell proliferation following treatment with NS-398 was used to assess whether the reduction in LNCaP viability was due to inhibitor cytotoxicity. Relative cell numbers were estimated by MTS assay as described previously (18). For both LNCaP and C4-2b cells $24 \mathrm{~h}$ treatment with $10 \mu \mathrm{M}$ NS-398 did not result in any significant toxic effect on cell proliferation following inhibitor removal (Student's t-test,

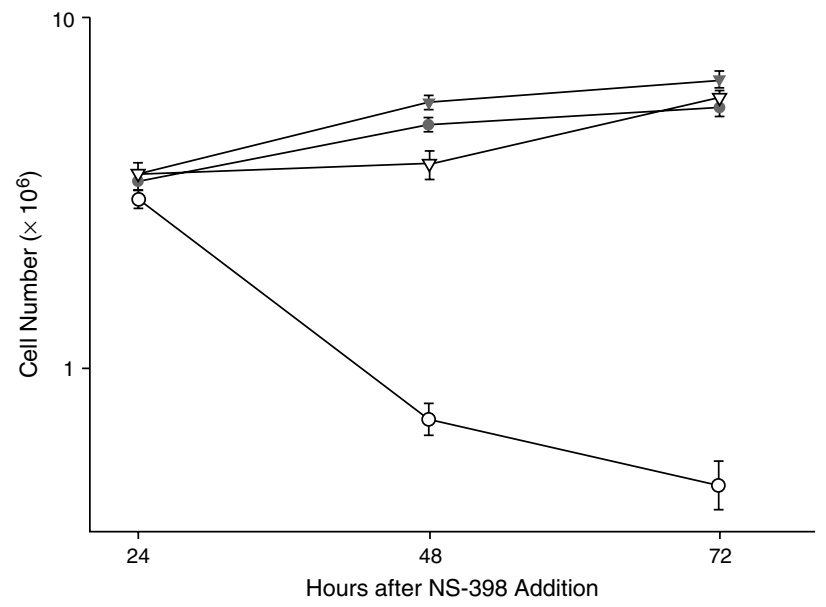

Fig. 1. NS-398 effects on proliferation of prostate epithelial cells in culture. LNCaP or LNCaP C4-2b cells $\left(1 \times 10^{6}\right)$ were plated in 6 well cluster plates for $24 \mathrm{~h}$ in standard medium, then medium was replaced with serum-free medium supplemented with $0.5 \mu \mathrm{g} / \mathrm{ml}$ BSA containing $10 \mu \mathrm{M}$ NS-398. Cells were cultured for an additional $72 \mathrm{~h}$ with samples taken at $24 \mathrm{~h}$ intervals. Cell number was determined by direct counting using trypan blue dye exclusion. Data represents mean of three separate experiments performed in duplicate. Closed triangle, $\mathrm{C} 4-2 \mathrm{~b}$ control; open triangle, $\mathrm{C} 4-2 \mathrm{~b}$, NS-398; closed circle, LNCaP control; open circle, LNCaP, NS-398. DMSO $(0.1 \%)$ was added to control cultures. Error bars $=$ SE of means.

$\mathrm{P}=0.059, \mathrm{LNCaP} ; \mathrm{P}=0.073, \mathrm{C} 4-2 \mathrm{~b})$. Treatment with NS-398 $(24 \mathrm{~h})$ resulted in $90 \%$ LNCaP cell survival following inhibitor removal and $48 \mathrm{~h}$ incubation in growth medium $\left(2.3 \times 10^{6} \pm 3.5 \times 10^{4}\right.$ control cells per well versus $2.1 \times 10^{6} \pm 3.5 \times 10^{4}$ treated cells per well) when compared with vehicle treated cells. C42 b cells exhibited $98 \%$ survival following NS-398 removal $\left(3.1 \times 10^{6} \pm 4.0 \times 10^{3}\right.$ control cells per well versus $2.9 \times 10^{6} \pm 4.1 \times 10^{3}$ treated cells per well). The vehicle $(0.1 \%$ DMSO) was non-toxic to the prostate tumor cells and had no effect on cell division (both cell lines showed greater than $98 \%$ survival following DMSO treatment compared with untreated cultures).

\section{NS-398 Induced Apoptosis}

To determine whether NS-398 induced apoptosis was responsible for the decrease in LNCaP cell viability, LNCaP and C4-2b cells were incubated with increasing NS-398 concentrations $(2.5-200 \mu \mathrm{M})$ for $72 \mathrm{~h}$ (data not shown). The minimal concentration that induced reproducible apoptosis in LNCaP cells, as assessed by DNA laddering, was used in subsequent apoptosis experiments $(10 \mu \mathrm{M})$. Internucleosomal DNA cleavage, an apoptosis hallmark, was assessed by genomic DNA agarose electrophoresis following $72 \mathrm{~h}$ treatment with $10 \mu \mathrm{M}$ NS-398. LNCaP cells, but not C4-2b cells demonstrated typical DNA laddering (Fig. 2A). Apoptosis inhibition by elevated COX-2 was reported as concomitant with inhibition of caspase-3 activation (21). Thus, in the 

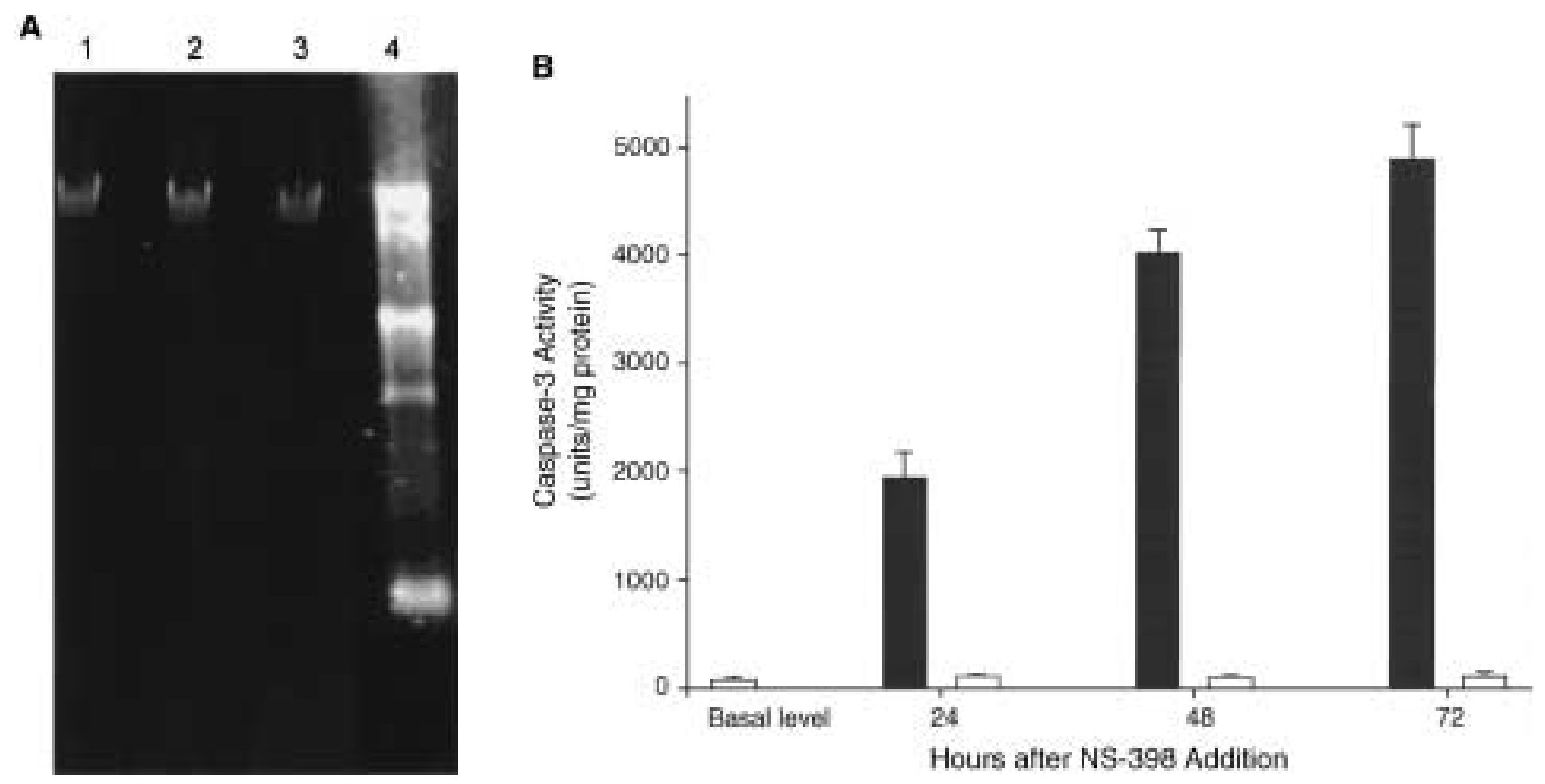

Fig. 2. NS-398 effects on apoptosis in LNCaP cells. Cells were cultured as in Fig. 1. At designated intervals adherent cells were harvested by gentle scraping and pooled with non-adherent cells floating in culture medium. Cells were collected by centrifugation then washed with PBS. (A) DNA laddering: Cells were collected following $72 \mathrm{~h}$ treatment with NS-398, then genomic DNA (20 $\mu \mathrm{g})$ was separated on $1.5 \%$ agarose gels using TAE buffer. DNA was visualized in the SYBR-green stained gel and photographed. Gel is representative of data from three separate experiments. Lanes 1-2, C4-2b; lanes 3-4, LNCaP; lanes 1-3, DMSO controls; lanes 2-4, NS-398 treatment $(10 \mu \mathrm{M})$ B). (B) Caspase-3 activity: Cells were collected following 48 h treatment with NS-398. $3 \mu \mathrm{g}$ total cellular protein from cell lysates was used to determine protease activity toward the synthetic peptide Asp-Glu-Val-Asp (DEVD). Free pNA produced by DEVD cleavage was quantified by absorbance at $405 \mathrm{~nm}$ using an ELISA plate reader. Caspase-3 activity is expressed pNA optical density units/mg total cell lysate protein. Open, LNCaP, DMSO control; closed, LNCaP, NS-398. Caspase-3 activity could not be detected in C4-2b cells and extremely low basal levels detected in zero hour LNCaP cultures was attributed to basal cell lysate protease activity, as this activity was lost upon $1 \mathrm{mM}$ protease inhibitor cocktail (Gibco/BRL) inclusion in the assay. Data are mean of three separate experiments performed in duplicate. Error bars $=$ SE of means.

present study apoptosis induction or inhibition was confirmed by caspase-3 activity assay. As seen in Fig. 2B LNCaP cells treated with NS-398 for $48 \mathrm{~h}$ exhibited caspase- 3 activity (ANOVA, $\mathrm{P}=<0.001$, when compared with LNCaP control). Basal caspase-3 activity, detected in zero hour LNCaP cultures was attributed to generalized protease activity, since this activity was abolished by addition of a protease inhibitor cocktail. There was no significant caspase-3 activity detected in C4-2b cells with or without NS-398 treatment (ANOVA, $\mathrm{P}=0.63$; Power $=0.51)$. C4-2b cells showed no apoptotic signs at NS-398 concentrations as high as $200 \mu \mathrm{M}$ (data not shown).

\section{NS-398 Effects on COX-2 and MIF Expression}

Under the described conditions, both LNCaP and C4$2 \mathrm{~b}$ constitutively express MIF and COX-2 as determined by Western and RT-PCR (Fig. 3). In C4-2b cells both MIF and COX-2 basal levels are elevated compared with LNCaP. These cells secrete approximately 2 fold more immunoreactive MIF protein and contain 4 fold more immunoreactive COX-2 protein than LNCaP cells (Fig. 3A and C, Student's t-test, $\mathrm{P}=0.022)$. NS-398 treatment $(10 \mu \mathrm{M})$ up-regulates both intracellular COX-2 protein (Fig. 3C; 2-fold, Student's t-test, $\mathrm{P}=0.026$ ) and COX-2 mRNA levels (Fig. 3D; 2 -fold, $P=0.01$ ) in C4-2b cells. In addition, NS-398 $(10 \mu \mathrm{M})$ up-regulates secreted MIF protein approximately 2 -fold in both LNCaP and C4-2b cells (Fig. 3A; Student's t-test, $\mathrm{P}=0.037$ for LNCaP and $\mathrm{P}=0.029$ for $\mathrm{C} 4-2 \mathrm{~b}$ ), while MIF mRNA levels increase 2.5 -fold in both LNCaP and C4-2b cells (Fig. $3 \mathrm{~B}, \mathrm{P}=0.01)$. MIF mRNA levels were observed to increase within $24 \mathrm{~h}$ of NS-398 treatment in both cell types (1.5-fold increase in gene expression ratio, Student's t-test, $\mathrm{P}=0.01$ ) and in C4-2b cells the NS-398 induced up-regulation of MIF and COX-2 expression continued through out the $72 \mathrm{~h}$ assay period.

\section{NS-398 Induces Neuroendocrine Phenotype in C4-2b Cells}

Microscopic observation of C4-2b cells treated with $10 \mu \mathrm{M}$ NS-398 indicated that treatment induces gradual changes in cellular morphology that began within $24 \mathrm{~h}$ exposure to NS-398 with greater than $20 \pm 3.3 \%$ of the total cells exhibiting neuroendocrine morphology. By $72 \mathrm{~h}, 70.8 \pm 4.5 \%$ of $\mathrm{C} 4-2 \mathrm{~b}$ treated cells became elongated with prominent dendrite-like cytoplasmic processes extending from the cytoplasm with some dendrite extensions forming 

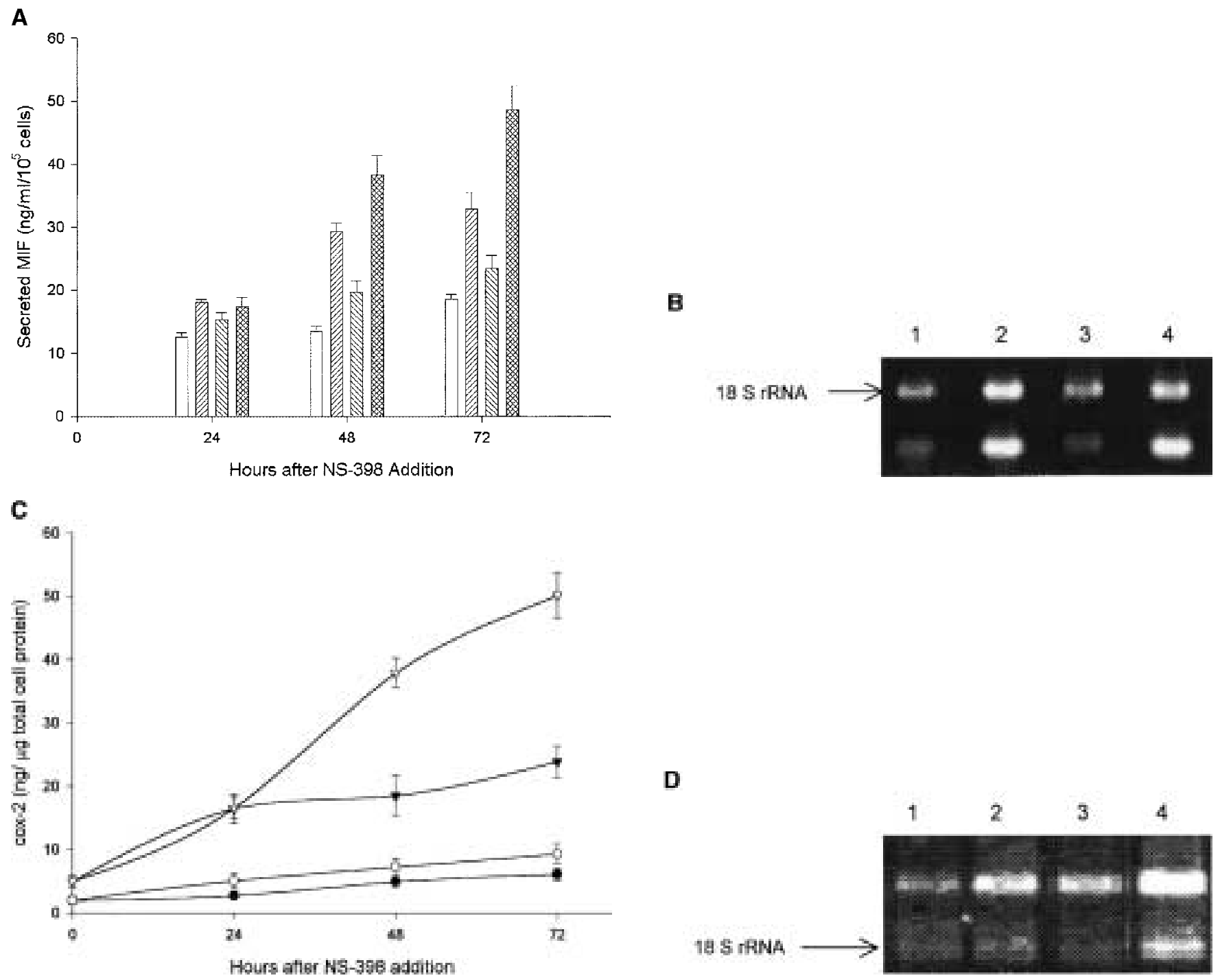

Fig. 3. NS-398 effects on MIF and cox-2 expression in LNCaP parental and C4-2b cells. Cells were cultured as in Fig. 1. At 24 h intervals culture medium was collected and cells harvested by gentle scraping. Half of the collected cells were used to isolate total protein, the remaining cells were used to isolate total RNA. (A) Secreted MIF levels: ELISA determined MIF in culture medium. Open, LNCaP control; hatched left, LNCaP NS-398; hatched right, C4-2b control; cross-hatched, C4-2b NS-398. Data are means of three separated experiments performed in triplicate. Error bars = SE of means. (B) MIF mRNA concentrations: MIF mRNA was determined by relative Q-RT-PCR. MIF specific primers and 18S rRNA primers: competimers (3:7) were simultaneously added to PCR reaction tubes and used to co-amplify MIF and 18S rRNA. PCR products were separated by agarose gel electrophoresis and areas as well as relative intensity were determined using AlphaImager. The area intensity of the MIF PCR product band ( 254 bp) was divided by area intensity of the 18S rRNA PCR product band (488 bp). Gel is representative of three independent experiments performed in triplicate. Lanes 1-2, C4-2b; lanes 3-4, LNCaP; lanes 1-3, DMSO controls; lanes 2-4, NS-398 treatment (10 $\mu \mathrm{M})$. Gel is representative of two independent experiments performed in triplicate. (C) Intracellular COX-2 levels: ELISA determined cell lysate COX-2. Closed circle, LNCaP control; open circle, LNCaP NS-398; closed triangle, C4-2b control; open triangle, C4-2b NS-398. Data are means of three separate experiments performed in triplicate. Error bars = SE of means. (D) COX-2 mRNA levels: COX-2 mRNA was determined by relative Q-RT-PCR. COX-2 specific primers and 18S rRNA primers:competimers (3:7) were simultaneously added to PCR reaction tubes and used to co-amplify COX-2 and 18S rRNA. PCR products were separated by agarose gel electrophoresis and areas and relative intensity determined using AlphaImager. The area intensity of the COX-2 PCR product band (696 bp) was divided by area intensity of the $18 \mathrm{~S}$ rRNA PCR product band (488 bp). Lanes 1-2, LNCaP; lanes 3-4, C4-2b; lanes 1-3, DMSO controls; lanes 2-4, NS-398 treatment $(10 \mu \mathrm{M})$. Gel is representative of three independent experiments performed in triplicate.

connections among neighboring cells (Fig. 4A). These morphological changes could be reversed by either removal of NS-398 and subsequent $48 \mathrm{~h}$ incubation in growth medium or by MIF neutralizing antibody (1:200 dilution) addition to growth medium along with NS-398 (data not shown).
Addition of either isotype specific goat IgGl control antibody (1:200 dilution) or cox-2 neutralizing antibody (160107, Cayman Chemical, 1:200 dilution) did not reverse these morphological changes indicating that this observation was related to elevated MIF concentrations seen in NS-398 treated C4-2b 
A

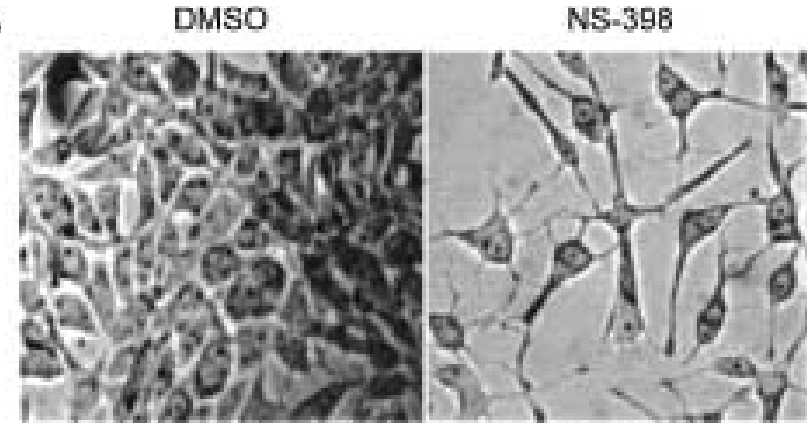

B

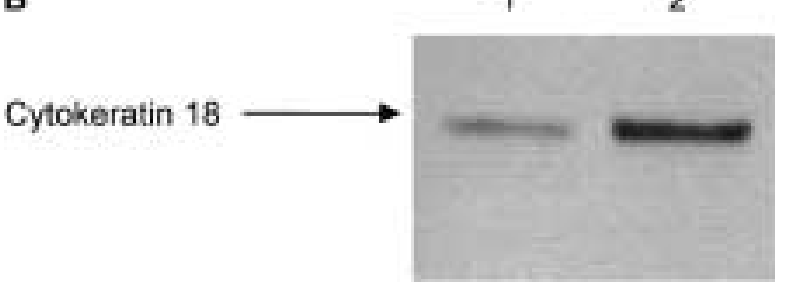

Fig. 4. NS-398 effects on morphology and neuron specific and epithelial cell specific protein expression. C4-2b cells were cultured with NS-398 $(10 \mu \mathrm{M})$ for $72 \mathrm{~h}$, samples were obtained every $24 \mathrm{~h}$. Cells were photographed and total cellular protein isolated. (A) Morphological changes in C4-2b: phase contrast photomicrograph of $72 \mathrm{~h} \mathrm{C4-2b}$ cultures (400X magnification), (left) $0.1 \%$ DMSO treated control C4-2b cells and (right) $10 \mu \mathrm{M}$ NS-398 treated cells. A low cell density area was photographed in the NS-398 cultures to visualize dendrite-like cytoplasmic processes. (B) Cytokeratin 18 in C4-2b cell lysate protein: Cytokeratin 18 was detected by Western blot analysis. $300 \mathrm{ng}$ of total protein was loaded per well. Lane 1, 0.1\% DMSO control; lane 2, $10 \mu \mathrm{M}$ NS-398. Cytokeratin-18 was quantified by image intensity analysis of Western blots using a digital imaging system. Cytokeratin-18 levels are expressed as arbitrary area intensity units (255 equivalent to black, 0 equivalent to white). Band intensity analysis determined a 2 -fold increase in cytokeratin 18 concentration in NS-398 treated cells $(8516 \pm 1558$, DMSO control; $20680 \pm 1760$, NS-398 treatment). Blot is representative of data from two independent experiments.

cells. This result indicates that the NS-398 induced change in $\mathrm{C} 4-2 \mathrm{~b}$ cellular morphology is in part mediated by elevated MIF concentrations. The observed morphological changes were similar to neu- roendocrine morphology prompting an analysis of prostate epithelial and neuron specific protein expression. NS-398 increases PSA and cytokeratin-18, as well as, neuron specific proteins chromogranin A and NSE as detected by ELISA and Western blots in C4-2b cell lysates (Table 1. and Fig. 4B). Chromogranin A and NSE could be detected in cell lysates from $72 \mathrm{~h}$ control cultures $(222.8 \pm 20.9$ and $139.3 \pm$ $22.8 \mathrm{pg} / \mathrm{ml} / 10^{5}$ cells, respectively). Following $72 \mathrm{~h}$ NS-398 treatment, C4-2b cells exhibited a greater than 5 -fold increase in neuron specific enolase $(\mathrm{P} \leq$ $0.001)$ and 3-fold increase in chromogranin A (P $\leq$ $0.001)$. In addition, following $72 \mathrm{~h}$ NS-398 treatment, these cells exhibited 2-fold increases in cytokeratin 18 (K18) as determined by Western blot intensity analysis (Fig. 4B; $\mathrm{P}=0.035$ ) and a 2 -fold increase in intracellular PSA $(P=0.005)$. Differentiation in prostate cancer cells is usually associated with cell growth inhibition and a decrease in prostate specific antigen (PSA) levels. NE differentiation was not seen in DMSO treated cultures suggesting that this phenotypic change is induced by NS-398. C4-2b cells reverted to epithelial like phenotype following removal of NS-398, replacement with growth medium and incubation at $37^{\circ} \mathrm{C}$ for $48 \mathrm{~h}$ (data not shown). C4-2b cells show neither altered morphological changes nor increases in neuron-specific markers when co-incubated with NS-398 and MIF neutralizing antibody (NSE, Student's t-test, $\mathrm{P}=0.072$, Power $=0.51$; Chromogranin A, Student's t-test, $P=0.059$, Power $=0.53$ ). The neuron-like morphology was not reversed when cells were co-incubated with NS-398 and isotype specific goat IgGl control antibody (1:200 dilution).

NS-398 Induces NF- $\kappa \beta$ and Down-regulates I $\kappa-\alpha$ Protein Expression in LNCaP C4-2b Cells

Experiments using NF- $\kappa \beta$ specific nuclear translocation inhibitor SN-50 showed that when active NF- $\kappa \beta$ is inhibited from entering the nucleus, MIF and COX-2 mRNA levels decrease $(65 \%$ and $70 \%$, respectively $\mathrm{P}=0.02$ ), which suggests that $\mathrm{NF}-\kappa \beta$ mediates NS-398 effects. Western blot analysis was used to elucidate whether NS-398 alters NF- $\kappa \beta$ protein concentrations within C4-2b cells. Based

Table 1. Expression of neuron-specific and prostate epithelial-specific proteins by C4-2b neuroendocrine-like cells

\begin{tabular}{cccc}
\hline Treatment & PSA & Chromogranin A & Neuron Specific Enolase \\
\hline Control & $13.6 \pm 2.4$ & $222.8 \pm 20.9$ & $139.3 \pm 22.8$ \\
NS-398 & $25.6 \pm 1.3$ & $732.8 \pm 48.8$ & $700.8 \pm 49.8$ \\
\hline
\end{tabular}

Cells were collected following $72 \mathrm{~h}$ treatment with $10 \mu \mathrm{M}$ NS-398 as described in Materials and Methods. Total cellular lysate was used to determine PSA, Chromogranin A and neuron-specific enolase by ELISA. ELISA data are expressed as mean ng/ml total cellular lysate $/ 10^{5}$ cells \pm SE of means. Data represents three separate experiments performed in triplicate. 
upon Western blot band intensities, there is no significant difference in basal concentrations of both NF- $\kappa \beta$ and its specific inhibitor, I $\kappa \beta-\alpha$, as detected in LNCaP and C4-2b cell lysates $(\mathrm{P}=0.06$, Power $=0.47$ ). However, $72 \mathrm{~h}$ NS-398 treatment increased NF- $\kappa \beta$ protein concentrations 3 -fold compared to DMSO treated controls in C4-2b cells (Fig. $5 \mathrm{~A}, \mathrm{P}=0.005$ ). Elevated NF- $\kappa \beta$ protein alone is not indicative of increased transcriptional activity. Increased NF- $\kappa \beta$ activity may actually result from decreased $\mathrm{I} \kappa \beta-\alpha$. The net affect of increased transcription factor along with a decrease in its specific inhibitor would be an increase in nuclear, active NF- $\kappa \beta$. Western blot analyses determined that NS-398 treatment both increased NF- $\kappa \beta$ and reduced active $\mathrm{I} \kappa \beta-\alpha 3$-fold in $\mathrm{C} 4-2 \mathrm{~b}$ cells $(\mathrm{P} \leq$ 0.001 , Student's t-test); indicating that in $\mathrm{C} 4-2 \mathrm{~b}$ cells NS-398 treatment results in a net increase in available, biologically active NF- $\kappa \beta$ (Fig. 5A). Western blot NF- $\kappa \beta$ analysis determines total NF$\kappa \beta$ concentration, but this assay does not determine transcription factor activity. NF- $\kappa \beta$ activity in NS-398 treated C4-2b cells was ascertained by electrophoretic mobility shift assay (EMSA). Double stranded oligonucleotides containing NF- $\kappa \beta$ consensus sequence (GGGGACTTTCC) tandem repeats were labeled with ${ }^{32} \mathrm{P}$. Nuclear extracts from DMSO control and NS-398 $(10 \mu \mathrm{M})$ treated C4-2b cultures were mixed with labeled oligonucleotides and the resulting DNA-protein complexes separated by non-denaturing polyacrylamide gel electrophoresis. Results show that NS-398 treatment increased active NF- $\kappa \beta$ (Fig. 5B, lane 1). Band intensity determined by densitometric analysis revealed that NS398 treatment results in a 2 -fold increase in NF- $\kappa \beta$ binding activity in C4-2b cells (Student's t-test, $\mathrm{P}=$ 0.002 ). Binding specificity was confirmed by unlabeled NF- $\kappa \beta$ oligonucleotide addition, which reduced detected binding activity (Fig. 5C, lane 2). Addition of MIF neutralizing antibody along with NS-398 resulted a 3-fold decrease in NF- $\kappa \beta$ as determined by EMSA (Student's t-test, $\mathrm{P}=\mathbf{0 . 0 0 2}$, lane 1 compared with lane 3, Fig. 5B), which indicates that NS-398 induced increases in MIF concentrations are partially responsible for increased NF- $\kappa \beta$ activity. Addition of isotype specific goat IgGl control antibody (1:200 dilution) did not alter NF- $\kappa \beta$ EMSA band intensities.

\section{Discussion}

Pro-inflammatory proteins, over-expressed in cells, may result in persistent activation of normally transiently activated genes, resulting in phenotypic changes that eventually lead to neoplasia development. Among the various pro-inflammatory proteins recently investigated, $\mathrm{COX}-2$ up-regulation is a frequent occurrence in a variety of tumors including the prostate $(4,22,23)$. A recent study has determined that COX-2 expression is 4 fold
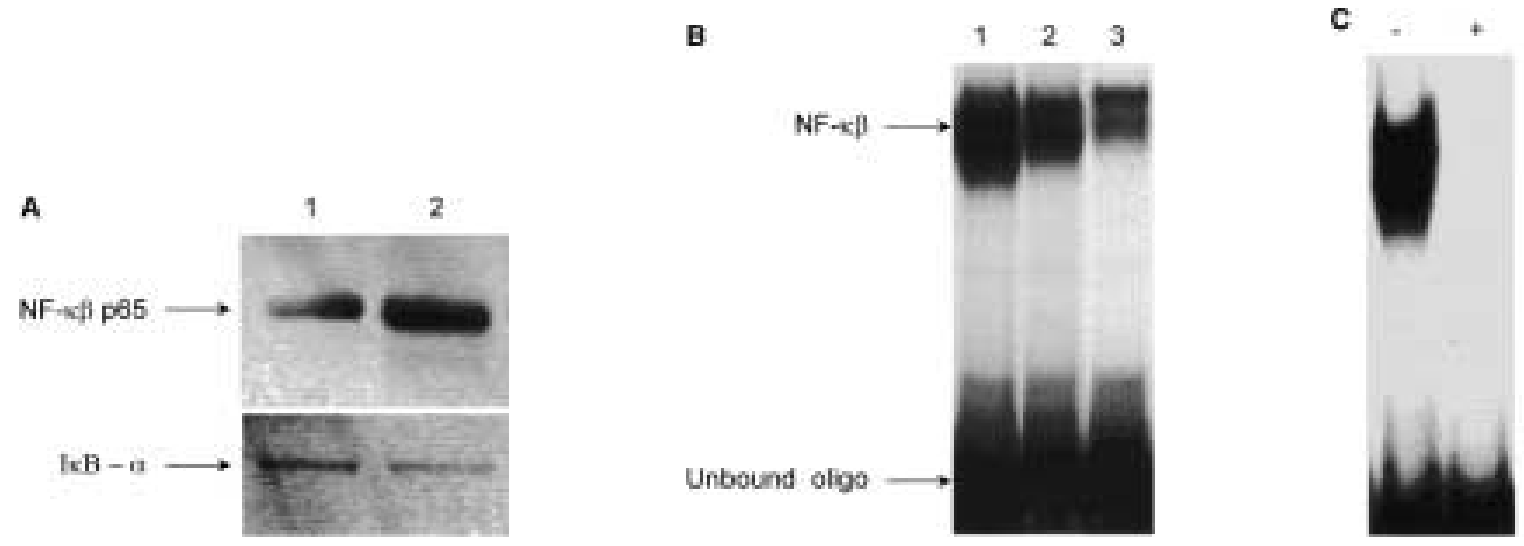

Competing align

Fig. 5. NS-398 effect on NF- $\kappa \beta$ and I $\kappa B-\alpha$ Expression in C4-2b Cells. C4-2b cells were cultured with NS-398 (10 $\mu$ M) for 72 h. (A) Western blot analysis: total cellular protein isolated and separated by SDS-PAGE. Protein was transferred to PVDF and NF- $\kappa \beta$ and $\mathrm{I} \kappa \mathrm{B}-\alpha$ detected by Western blot analysis. I $\kappa \mathrm{B}-\alpha$ was detected using an antibody specific for the activated form. Blots are representative of data from two independent experiments. Lane 1, C4-2b DMSO control; lane 2, C4-2b, $10 \mu \mathrm{M}$ NS-398. Upper bands represents NF- $\kappa \beta$ p65, lower bands represents $\mathrm{I} \kappa \mathrm{B}-\alpha$. (B) Electrophoretic mobility assay (EMSA): double stranded oligonucleotides containing NF- $\kappa \beta$ consensus sequence (GGGGACTTTCC) tandem repeats were labeled with ${ }^{32} \mathrm{P}$. Nuclear extracts from DMSO control and NS-398 $(10 \mu \mathrm{M})$ treated C4-2b cultures were mixed with labeled oligonucleotides and the resulting DNA-protein complexes separated by non-denaturing $6 \%$ polyacrylamide gel electrophoresis. NS-398 added to C4-2b cells increases NF- $\kappa \beta$ binding to NF- $\kappa \beta$ DNA consensus sequence oligonucleotide as determined by EMSA; lane 1, NS-398 (10 $\mu \mathrm{M})$; lane 2, DMSO control; lane 3, NS-398 (10 $\mu$ M) and MIF neutralizing antibody (1:200 dilution). Autoradiograph is representative data from two independent experiments. (C) Electrophoretic mobility assay (EMSA) NF- $\kappa \beta$ specificity: reactions were performed as in Fig. 5 B except that addition of excess unlabeled competitor NF- $\kappa \beta$ DNA consensus sequence oligonucleotide (800 ng) was added to NS-398 (10 $\mu \mathrm{M})$ treated nuclear extracts. Lane (-) NS-398 $(10 \mu \mathrm{M})$ treated nuclear extracts without addition of unlabeled competitor sequence; $(+)$ NS-398 (10 $\mu \mathrm{M})$ treated nuclear extracts with addition of unlabeled competitor sequence. Autoradiograph is representative of data from two independent experiments. 
higher in prostate cancer compared with BPH (4). In addition, this same study determined that COX2, localized intracellularly to luminal glandular cell membranes in well-differentiated tumors, became primarily cytoplasmic in poorly differentiated tumors (4). It is possible that sustained prostaglandin generation, mediated by elevated COX-2, is a critical step in the multi-step genetic processes that eventually result in prostate tumorigenesis. Thus, it is important to understand the mechanisms regulating $\mathrm{COX}-2$ in prostate cells and its role in tumor growth.

Initially androgen ablation successfully shrinks primary and metastatic prostate lesions by inducing apoptosis in androgen-responsive prostate cancer cells. However, androgen ablation may select for cells already over-expressing pro-inflammatory proteins, in part, for their ability to resist apoptosis. Prostate cancer cells are extraordinarily heterogeneous, suggesting that perhaps various diverse signaling pathways may be involved in apoptosis resistance evolution. If $\mathrm{COX}-2$ inhibitors are to be useful in prostate cancer treatment they should induce apoptosis without inducing additional proinflammatory mediators. Increased COX-2 protein levels in epithelial cells have been shown to inhibit apoptosis and increase malignant cell invasiveness (15). Thus, it has been suggested that COX-2 inhibition may be an effective cancer chemotherapeutic modality. NSAID dosage required to achieve tumorigenesis inhibition is much higher than that required to reduce COX-2 enzyme activity suggesting that these inhibitors may have multiple modes of action (1). Since short term NS-398 exposure (24 h, Fig. 1) did not affect LNCaP tumor cell viability this drug's effects on LNCaP cells cannot be attributed cytotoxicity alone. Apoptosis was identified previously as a mechanism responsible for the NS398 induced decline in viable LNCaP cells (17). The data presented here continue to support COX-2 inhibitor use as chemotherapeutic agents for prostate cancer prevention, as LNCaP cells are stimulated to undergo apoptosis when exposed to NS-398 for periods of at least $48 \mathrm{~h}$. However, use of COX-2 inhibitors for prostate cancer chemotherapy is indicated with the caveat that it can be determined that the patient does not currently have aggressive prostate cancer. The results of the present study indicate that COX-2 inhibitors may trigger a "survival response" in certain aggressive prostate cancer cells, as exemplified by the C4-2b LNCaP subline. This survival response includes pro-inflammatory cytokine MIF up-regulation, as well as an apparent MIF specific neuroendocrine phenotype induction. The present results demonstrate that NS-398 treatment does not induce apoptosis and appears to stimulate neuroendocrine differentiation, MIF up-regulation and increased NF- $\kappa \beta$ activity in C4-2b cells. Thus, in the prostate localized cellular response to COX-2 inhibitors may be contrary to the current paradigm if aggressive prostate cancer cells are present. As suggested by a recent study by Subbarayan and co-workers, COX-2 expression in the prostate may depend upon the presence of cytokines and other growth factors found in the tumor microenvironment (23). The present results demonstrate that MIF may be a cytokine that regulates COX-2 expression and may be partially responsible for apoptosis resistance and malignant neuroendocrine differentiation seen in the $\mathrm{C} 4-2 \mathrm{~b}$ cells. Previous experimental results from other laboratories determined that fibroblasts (Rat-1/mycER) and macrophages (RAW264.7) treated with MIF were able to overcome p53-dependent apoptosis (24). Thus, a role for MIF as a link between inflammation and cancer has been established with chronic NF- $\kappa \beta$ activation and bypass of p53 induced apoptosis as mechanisms that could contribute to tumorigenesis.

This laboratory's focus is MIF's role in prostate function. MIF is a critical immune system component and acts in concert with glucocorticoids to regulate inflammation and immunity (25). Previous work from this laboratory demonstrated that elevated MIF levels are associated with metastatic prostate cancer (5). MIF is an unusual pro-inflammatory cytokine since it is induced by glucocorticoids and modulates cytokine production in response to hormone levels (25). Based upon its role in promoting inflammation under anti-inflammatory conditions, it was hypothesized that MIF levels would be elevated in response to NS-398. NS-398 has been shown to stimulate both COX-2 mRNA and protein synthesis (26). The present study's results link COX-2 inhibition with elevated MIF secretion in prostate cells. MIF expression may be stimulated in response to COX-2 inhibition so that other pro-inflammatory and survival genes regulated by MIF are activated. MIF synthesis and release, induced by glucocorticoids has been documented in other cell systems (25). A recent study has documented that MIF up-regulates COX-2 activity (14). Thus, MIF appears to be a proinflammatory cytokine whose activity is implicated in a wide range of regulatory actions involved in the inflammatory cascade, including COX-2 upregulation. The experimental results delineated in the current paper suggest that induction of MIF release, at least in prostate cancer cells, may be a generalized response to an anti-inflammatory agent; as evidenced by the initial MIF up-regulation seen in LNCaP and C4-2b cells following NS-398 treatment.

Of the possible transcription factors that could regulate COX-2 and MIF this study focused on NF- $\kappa \beta$ because the human COX-2 and MIF promoters contain a regulatory DNA sequence to which NF- $\kappa \beta$ binds $(27,28)$. It has been suggested that NSAID ability to act as tumor growth suppressors may be in part related to their ability to inactivate NF- $\kappa \beta$ (29-31). In addition, MIF was reported to inhibit hydrocortisone induced effects on the NF- $\kappa \beta$ signal transduction pathway (32), therefore the potential 
relationship between COX-2 inhibition, NF- $\kappa \beta$ activation and MIF in the prostate was explored. Constitutive NF- $\kappa \beta$ activation in prostate tumor cells may increase anti-apoptotic gene expression, thereby contributing to malignant phenotype development. In the present study, we demonstrated that reduction in available active NF- $\kappa \beta$ due to $\mathrm{SN}-50$ treatment decreased MIF and COX-2 expression in C4-2b cells, thus implicating NF- $\kappa \beta$ in these processes. $\mathrm{I} \kappa \mathrm{B}-\alpha$ binding to NF- $\kappa \beta$ masks the transcription factor's nuclear localization signals and inhibits NF- $\kappa \beta$ activity. $\mathrm{SN}-50$ is a bioactive peptide that binds active NF- $\kappa \beta$ nuclear translocation signal, acting in a manner similar to I $\kappa \mathrm{B}-\alpha$. MIF antagonizes hydrocortisone's effect on NF- $\kappa \beta$ by inhibiting the hydrocortisone induced increases in cytosolic I $\kappa \mathrm{B}-\alpha$ (32). Thus, it is possible that the elevated MIF levels induced by the antiinflammatory drug, NS-398, exerts a similar inhibitory effect on cytosolic $\mathrm{I} \kappa \mathrm{B}-\alpha$ in prostate epithelial cells. In addition, increased MIF secretion may be a generalized cellular response to anti-inflammatory agents. The results presented here extend MIF's proinflammatory action as this cytokine is up-regulated in response to a COX-2 specific inhibitor. Although the detailed inhibitory mechanism is not yet determined, the results reported here, clearly indicate a role for NF- $\kappa \beta$ in these processes.

Neuroendocrine (NE) differentiation within prostate tumors has been proposed as a contributing factor in prostate cancer disease progression (33). NE differentiation, as reflected by increased expression of NE secretory products is associated with poor prognosis, tumor progression and androgen-unresponsiveness (33). In most instances, prostate cancer cell NE differentiation results in a decrease in both proliferation and PSA secretion. However, dual expression of epithelial characteristics (PSA) and NE markers has been demonstrated in prostate cancer cells $(34,35)$. Although these cells display NE characteristics, the malignant NE differentiated cells should be distinguished form the normal prostate NE cell. Normal NE cells are thought to be terminally differentiated and post-mitotic. Several prostate cancer cell lines will manifest a mixture of NE and epithelial features, but still proliferate (34). In these instances certain NE substances were expressed, but not necessarily the complete normal NE phenotypic repertoire. This phenotypic shift generates a cancer cell that is more adaptable to environmental changes, including androgen depletion, because NE differentiation follows androgenunresponsive regulatory modes. If the NE phenotype is only partially adopted and the cells retain their proliferative capacity, then malignant progression could be sustained. Increases in $\mathrm{K} 18$ and chromogranin A have been noted in LNCaP cells with similar NE morphological changes (36). The C4-2b experimental results, reported in the current study, support these recent study results, which suggest that MIF is a unique neuroendocrine mediator (37).
The results of present study continue to support a role for pro-inflammatory proteins in prostate cancer progression. In summary, NS-398 treatment of LNCaP prostate cells induced the typical, expected apoptosis response with the exception of MIF up-regulation. However, under all conditions studied NS-398 does not induce C4-2b apoptosis. Rather, these data demonstrate that the COX-2 inhibitor, NS-398, induces a pro-inflammatory effect on C4-2b cells including upregulation of the pro-inflammatory cytokine, MIF, increased NF- $\kappa \beta$ activity and a unique malignant NE differentiation. Further studies should be performed to elucidate the precise role of NF- $\kappa \beta$ and pro-inflammatory gene expression, in particular MIF, in prostate cancer.

\section{Acknowledgements}

This material is based upon work supported by the Office of Research and Development and the Medical Research Service, Department of Veterans Affairs. The author would like to thank W. Webster, Pharm. D. and M. Tannenbaum, M.D. for their critical review of the manuscript.

\section{References}

1. Norrish AE, Jackson RT, McRae CU. (1998) Non-steroidal anti-inflammatory drugs and prostate cancer progression. Int J. Cancer 77: 511-515.

2. Williams CS, Mann M, DuBois RN. (1999) The role of cyclooxygenase in inflammation, cancer and development. Oncogene 18: 7908-7916.

3. Gupta S, Srivastava M, Ahmad N, Bostwick DG, Mukhtar H. (2000) Over-expression of cyclooxygenase-2 in human prostate adenocarcinoma. Prostate 42: 73-78.

4. Madaan S, Abel PD, Chaudhary KS, et al. (2000) Cytoplasmic induction and over-expression of cyclooxygenase- 2 in human prostate cancer: implications for prevention and treatment. British J. Urol. Int. 86: 736-741.

5. Meyer-Siegler K, Hudson PB. (1996) Enhanced expression of macrophage migration inhibitory factor in adenocarcinoma metastases. Urology 48: 448-452.

6. Giardiello FM, Hamilton SR, Krush AJ, et al. (1993) Treatment of colonic and rectal adenomas with sulindac in familial adenomatous polyposis. N. Engl. J. Med. 328: 1313-1316.

7. Elder DJE, Paraseva, C. (1997) NSAIDs to prevent colorectal cancer: a question of sensitivity. Gastroenterology 113: 19992008.

8. Aimmermann KC, Sabia M, Weber A, et al. (1999) Cyclooxygenase-2 expression in human esophageal carcinoma. Cancer Res. 59: 198-204.

9. Meyer-Siegler K, Fattor RA, Hudson PB. (1998) Expression of macrophage migration inhibitory factor in the human prostate. Diagnos. Mol. Pathol. 7: 44-50.

10. Williams CS, Tsujii M, Reese J, et al. (2000) Host cyclooxygenase-2 modulates carcinoma growth. J. Clin. Invest. 105: 1589-1594.

11. Joki T, Heese O, Nikas DC, et al. (2000) Expression of cyclooxygenase 2 (COX-2) in human glioma and in vitro inhibition by a specific COX-2 inhibitor, NS-398. Cancer Res. 60: $4926-4931$.

12. Liu XH, Kirschenbaum A, Yao S, et al. (1999) Upregulation of vascular endothelial growth factor by cobalt chloride-stimulated hypoxia is mediated by persistent induction of cyclooxygenase- 2 in metastatic human prostate cancer cell line. Clin. Exp. Metastasis 17: 687-694. 
13. Smith WL, Garavito RM, DeWitt, DL. (1996) Prostaglandin endoperoxide $\mathrm{H}$ synthases (Cyclooxygenases)-1 and -2. $J$. Biol. Chem. 271: 33157-33160.

14. Sampey AV, Hall PH, Mitchell AR, et al. (2001) Regulation of synoviocyte phospholipase A2 and cyclooxygenase 2 by macrophage migration inhibitory factor. Arthritis Rheum. 44: 1273-1280.

15. Attiga FA, Fernandez PM, Weeraratna AT, et al. (2000) Inhibitors of Prostaglandin Synthesis Inhibit Human Prostate Tumor Cell Invasiveness and Reduce the Release of Matrix Metalloproteinases. Cancer Res. 60: 4629-4636.

16. Thalmann GN, Anezinis PE, Chang S-M. (1994) Androgen-independent cancer progression and bone metastasis in LNCaP model of human prostate cancer. Cancer Res. 54: 2577-2581.

17. Liu X-H, Yao S, Kirschenbaum A, Levine AC. (1998) NS-398, a Selective Cyclooxygenase-2 Inhibitor, Induces Apoptosis and Down-Regulates bcl-2 Expression in LNCaP Cells. Cancer Res. 58: 4245-4249.

18. Meyer-Siegler K. (2000) Macrophage Migration Inhibitory Factor Increases MMP-2 Activity in DU-145 Prostate Cells. Cytokine 12: 914-921.

19. Meyer-Siegler K. (2000) Increased Stability of Macrophage Migration Inhibitory Factor (MIF) in DU-145 Prostate Cancer Cells. J. Interferon and Cytokine Res. 20: 769-778.

20. Bradford MM. (1976) A Rapid and Sensitive Method for the Quantitation of Microgram Quantities of Protein Utilizing the Principle of Protein-Dye Binding. Anal. Biochem. 72: 248254.

21. Chang YW, Jakobi R, McGinty A, et al. (2000) Cyclooxygenase 2 promotes cell survival by stimulation of dynein light chain expression and inhibition of neuronal nitric oxide synthase activity. Mol. Cell. Biol. 20: 8571-8579.

22. Lim JW, Kim H, Kim KH. (2001) Nuclear Factor- $\kappa \beta$ regulates cyclooxygenase-2 expression and cell proliferation in human gastric cancer cells. Lab. Invest. 81: 349-360.

23. Subbarayan V, Sabichi AL, Llansa N, et al. (2001) Differential expression of cyclooxygenase- 2 and its regulation by tumor necrosis factor- $\alpha$ in normal and malignant prostate cells. Cancer Res. 61: 2720-2726.

24. Hudson JD, Shoaibi MA, Maestro R, et al. (1999) A Proinflammatory cytokine inhibits p53 tumor suppressor activity. J. Exp. Med. 190: 1375-1382.

25. Calandra T, Bernhagen J, Metz CN. (1995) MIF as a glucocorticoid-induced modulator of cytokine production. Nature 377: 68-71.
26. Yuan C-J, Mandal AK, Zhang Z, Mukherjee AB. (2000) Transcriptional regulation of cyclooxygenase-2 gene expression: novel effects of nonsteroidal anti-inflammatory drugs. Cancer Res. 60: 1084-1091.

27. Boolbol SK, Dannenberg AJ, Chadbum A, et al. (1996) Cyclooxygenase-2 overexpression and tumor formation are blocked by sulindac in a murine model of familial adenomatous polyposis. Cancer Res. 56: 2556-2560.

28. Kozak CA, Adamson MC, Buckler CE, et al. (1995) Genomic cloning of mouse MIF (macrophage inhibitory factor) and genetic mapping of the human and mouse expressed gene and nine mouse pseudogenes. Genomics 27: 405-411.

29. Palayoor ST, Youmell MY, Calderwood SK, Coleman CN, Price BD. (1999) Constitutive activation of $\mathrm{I} \kappa \mathrm{B}-\alpha$ and NF- $\kappa \beta$ in prostate cancer cells is inhibited by ibuprofen. Oncogene 18: 7389-7394.

30. Saha D, Datta PK, Sheng H, et al. (1999) Synergistic induction of cyclooxygenase-2 by transforming growth factor-betal and epidermal growth factor inhibits apoptosis in epithelial cells. Neoplasia 1: 508-517.

31. Yan Z, Subbaramaiah K, Camilli T, et al. (2000) Benzo[a]pyrene Induces the Transcription of Cyclooxygenase-2 in Vascular Smooth Muscle Cells: Evidence for the Involvement of Extracellular Signal-Regulated Kinase and NF- $\kappa \beta$. J. Biol. Chem. 275: 4949-4955.

32. Daun JM, Cannon JG. (2000) Macrophage migration inhibitory factor antagonizes hydrocortisone-induced increases in cytosolic $\mathrm{I} \kappa \mathrm{B}-\alpha$. Am. J. Physiol. Regul. Integr. Comp. Physiol. 279: R 1043-R 1049.

33. Abrahamsson P-A. (1999) Neuroendocrine cells in tumor growth of the prostate. Endocrine-Related Cancer 6: 503-519.

34. Cohen RJ, Glezerson G. (1992) Prostate specific antigen and prostate acid phosphatase in neuroendocrine cells of prostate cancer. Archives of Pathol. Lab. Med. 116: 65-66.

35. Chiao JW, Hsieh TC, Xu W, Sktarew RJ, Kancherla R. (1999) Development of human prostate cancer cells to neuroendocrine-like cells by interleukin-1. Int. J. Oncol. 15: 10331037.

36. Hsieh TC, Xu W, Chiao JW. (1995) Growth regulation and cellular changes during differentiation of human prostatic cancer LNCaP cells as induced by T-lymphocyte-conditioned medium. Exp. Cell Res. 28: 137-143.

37. Fingerle-Rowson GR, Bucala R. (2001) Neuroendocrine properties of macrophage migration inhibitory factor (MIF). Immunol. Cell Biol. 79: 368-375. 